\title{
Modeling and Analysis of Injection Moulding Process Parameters for Plastic Gear Industry Application
}

\author{
Nik Mizamzul Mehat, ${ }^{1,2}$ Shahrul Kamaruddin, ${ }^{2}$ and Abdul Rahim Othman ${ }^{2}$ \\ ${ }^{1}$ Department of Mould Technology, Kolej Kemahiran Tinggi MARA, Balik Pulau, Genting, 11000 Balik Pulau, Penang, Malaysia \\ ${ }^{2}$ School of Mechanical Engineering, Universiti Sains Malaysia, Engineering Campus, 14300 Nibong Tebal, Penang, Malaysia
}

Correspondence should be addressed to Shahrul Kamaruddin; meshah@eng.usm.my

Received 18 April 2013; Accepted 8 May 2013

Academic Editors: A. Gomez and J. Wei

Copyright (C) 2013 Nik Mizamzul Mehat et al. This is an open access article distributed under the Creative Commons Attribution License, which permits unrestricted use, distribution, and reproduction in any medium, provided the original work is properly cited.

\begin{abstract}
The performance of plastic gears in wide variety of power and motion transmission applications is rather limited due to weak mechanical properties and divergent mechanism of failures. A methodical simulation is carried out to analyze the gear performance with various gating system types, gate locations, and processing parameters via grey-based Taguchi optimization method. With the obtained optimum results in simulation stage, the flow patterns of polymer melt inside the mould during filling, packing, and cooling processes are studied and the plastic gear failures mechanism related to processing parameters are predicted. The output results in the future can be used as guidance in selecting the appropriate materials, improving part and mould design, and predicting the performance of the plastic gear before the real process of the part manufacturing takes place.
\end{abstract}

\section{Introduction}

Gears have been in use for more than three thousand years and commonly utilized in power and motion transmission under different loads and speeds. Due to the fiscal and practical advantages, the demand of using plastics in gearing industry is significantly increased and indubitably continues in the future. In comparing with metal gears, plastic gears have several advantages such as light weight, noiseless running, resistance to corrosion, lower coefficients of friction, and ability to run under none lubricated conditions $[1,2]$. Plastic gears can be produced by hobbing or shaping, likewise to metal gears or alternatively by injection moulding. With the continuous expansion of technology, plastic injection moulding bears itself to considerably more economical means of mass production to meet the rapidly rising market demand of plastic gearing in various applications. Injection moulded plastic gears have been used with success in the automotive industry, office machines, and household utensils, in food and textile machinery, as well as a host of other applications' areas [3]. Unlike metal gears, the potential uses of plastic gear, however, are rather limited due to weak mechanical properties, poor heat conductors, and tendency to undergo creep [4]. Apart from that, the plastic gear tooth experiences complex stresses during service and can fail by divergent mechanism. Investigations on plastic gear failures were extensively conducted. Senthilvelan and Gnanamoorthy [5] observed different types of failures on the Nylon 66 spur gears such as gear tooth wear, cracking at the tooth surface, tooth root cracking, and severe shape deformation. In the review work of Breeds et al. [6] and Hooke et al. [7], a sharp increase in wear loss over the addendum and dedendum of acetal gears is also observed to be strikingly different resulting from the differences in friction forces and increasing torque on each gear face during the running operation. Despite wear failure, plastic base gears, in addition, are sensitive to temperature due to heat generation during service which resulted in surface fatigue and fatigue cracking at tooth root acceleration [8]. On the other report of Osman and Velex [9], plastic gears can also fail due to contact fatigue or surface pitting as a result of dynamic tooth loads during the running operation.

Referring to the modes of failures, there are many factors contributing to the occurrence of plastic gear deficiencies. Material selection for the gears in instance is a critical decision in manufacturing the plastic gear by using injection 
moulding process as some plastic gear failures are caused by poor material selection. There are several different types of nylon (e.g., Nylon 6, Nylon 6/6, and Nylon 12) widely used in gear production that offer great toughness and wear well against other plastics and metals. Terashima et al. [10] reported that nylon materials lose their tensile strength within the range of $5-10 \%$ when exposed to a temperature increase of $10^{\circ} \mathrm{C}$ each. Furthermore, Nylon $6 / 6$ has poor thermal properties with low heat conductivity and large thermal expansion. Under high load and high speed, these characteristics can lead to local accumulations of heat, tooth wear, and decreased performance. In contrast, acetal is strong, has good resistance to creep and fatigue, has a low coefficient of friction, and is resistant to abrasion and chemicals [11]. However, acetal is so brittle that it has a low level of resistance to shock load compared to nylon and also known to be noisy under greaseless condition [12].

Apart from material selection, a proper part or mould design also plays a major role in getting the most out of plastic gears. A high quality moulded plastic gear starts with the design and construction of a high quality plastic gear mould. The mould shall always have proper cooling channels, venting, properly sized gates and runners, ample coring and ejection capabilities, quality mould surface finish, precision fits and tolerances, concentricity between mould components, and proper mould material selection. Any misjudgment in the part and mould design can lead to disastrous consequences on the plastic gear produced and cause subsequent modifications in the production line, indirectly incurring high production cost [13]. In the research conducted by Luscher et al. [14], the number of gates, if kept small, was shown to have a strong influence on the periodicity of both run-out and long-term transmission error on moulded polyketone gears. However, the gating scheme had minimal influence on the total magnitude of the errors for the same gears.

As plastic materials exhibit extremely convoluted properties, the complexity of the moulding process makes it very challenging to attain the desired gear part properties. The intricacy of injection moulding process in producing a wide range of parts with complex shape including those with tight tolerances $[15,16]$ has created a very intense effort to keep the quality characteristic of moulded plastic gear under control. Even if it is possible to select an optimal material for a specific gear task based on the properties such as strength, wear, stiffness, damping, and noise production, due to the complexity of injection moulding process which involving many processing parameters, such as pressure, temperature, and time, improper setting of processing parameters could negatively affect the final quality of the moulded plastic gear. In fact, the optimum properties of the plastic material with the most innovative part and mould design cannot be achieved and become meaningless without optimum processing parameters during the gear manufacturing. In addition, poor processing practices relying on experience, intuition, or trial and error in obtaining information regarding the processing parameters will also create the conditions for gear failure modes that could not be predicted or accounted for by even the most prudent of designers.
TABLE 1: Mesh statistic of gear model.

\begin{tabular}{lc}
\hline Mesh statistic & \\
\hline Number of elements & 537216 \\
Minimum aspect ratio & 1.156 \\
Maximum aspect ratio & 19.709 \\
Average aspect ratio & 1.547 \\
Match percentage & $83.3 \%$ \\
Reciprocal percentage & $68.1 \%$ \\
\hline
\end{tabular}

Be acquainted with the importance of the factors mentioned above on the final quality of moulded plastic gears; therefore, by intriguing the evolution of injection moulding flow analysis simulation packages available in the market nowadays, this research is conducted to study the effect of the types of gating system and gate locations on the quality of a moulded plastic gear as well as on the processing parameters. An attempt has also been made to identify the crucial processing parameters affecting the quality characteristics of plastic gear with the optimized gating system and determine the optimum level of injection moulding parameters for multiresponse characteristics of plastic gear using grey relational analysis coupled with Taguchi optimization method. With the obtained optimum results in simulation stage, the flow patterns of polymer melt inside the mould during filling, packing, and cooling processes can be studied and the plastic gear failures mechanism related to processing parameters can be predicted. The output results in the future can be used as a guidance to facilitate the engineers/designers in selecting the appropriate materials, improving part and mould design as well as predicting the performance of the plastic gear part before the real process of the part manufacturing takes place.

\section{Experimental Procedures}

2.1. Simulation Model and Material. Preliminary study of injection moulding flow analysis is undertaken by using moldflow plastic insight (MPI) version 6.1 software. For the gear three dimension (3D) geometrical drawing, it was initially done in SolidWorks (Figure 1) and further imported to MPI for injection moulding analysis simulation. The spur gear design which is compliant to American Gears Manufacturers Association (AGMA) standards was used. The details geometry and specification for the gear are shown in the Figure 2. In order to run the MPI analysis, the gear model must have an appropriate finite element mesh created. In this study, the gear model is meshed using 3D mesh technology [17]. Table 1 shows the meshing information of the gear simulation model. The crystalline thermoplastic polypropylene (PP) is specified for the meshed gear model. The PP manufacturer is Idemitsu Petrochemical Co. Ltd.; the trade name is Polypro J2000G.

2.2. Preliminary Filling Analysis of Gear Model. After creating the initial 3D mesh for the gear model, a preliminary filling analysis is conducted to forecast and visualize the filling pattern or the transient progression of the polymer flow 


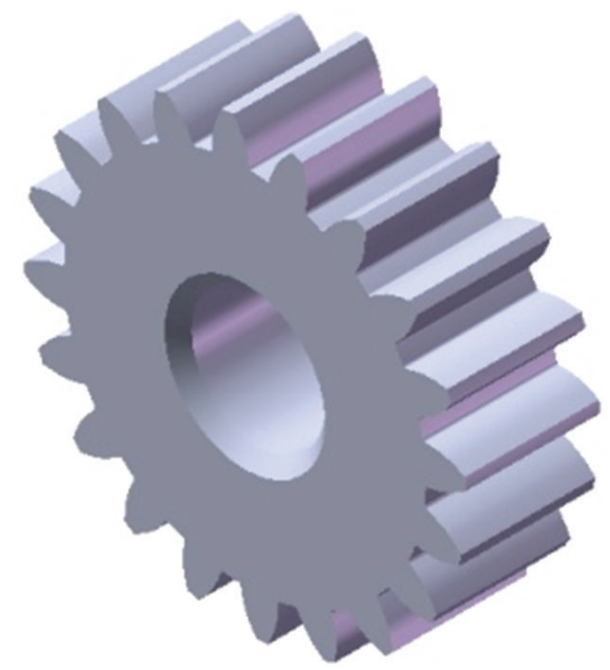

Figure 1: 3D model of spur gear.

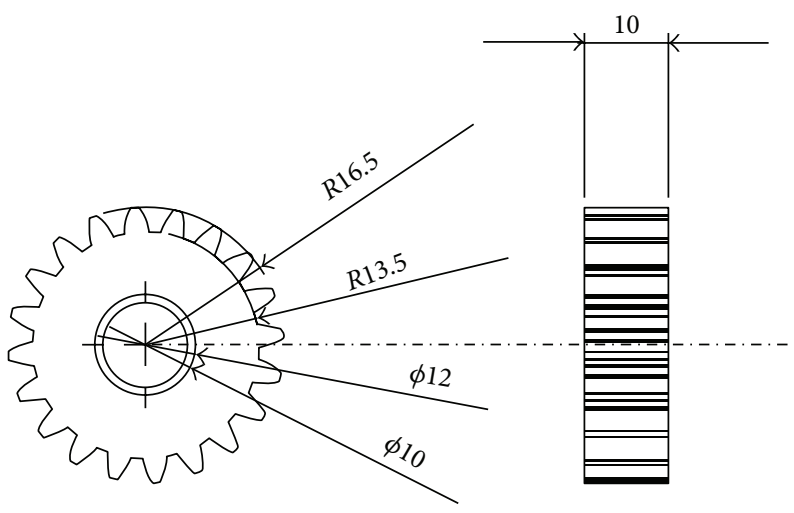

Figure 2: Geometry and specification of spur gear: module $=1.5$; pressure angle $=20^{\circ}$; number of teeth $=20$; face width $=10 \mathrm{~mm}$.

front within the feed system and mould cavity before the optimization of processing parameters takes place. Filling pattern plays an important role in determining and identifying any potential aesthetic issues such as short shot, hesitation, air traps, and weld line due to wrongly gear types and locations selected. Selecting on location of gating system not only affects flow pattern but also significantly influences on anisotropic or directional shrinkage result from flowinduced orientation and eventually contributes to warpage and residual stresses in moulded gear.

Three different types and locations of gate for the model gear as shown in Figure 3 are studied in order to optimize the filling of plastic material into the cavity of the gear part. The best gate type and location for the polymer fill inside the cavity will be selected. The selected gating system should produce a balanced flow front within the part, with no underflow or over packing effects as well as unidirectional.

Referring to the Figure 4, inside gating system, the material is injected in one spot and from there the melt material flows to fill out the cavity. This creates a weld line opposite to the gate. The area where the weld is located will be of limited strength as the plastic material is less fluid at that point in time. An unbalanced filling around a core which results in deflection in the core can be seen. Due to the fact that, shrinkage of the material in the direction of the flow will be different from that perpendicular to the flow, a side gated gear will be somewhat elliptical rather than round. On the other hand, in gear model with diaphragm gate (Figure 5), the injection of material is in all directions at the same time which is important for the concentricity of the gear. There is no presence of a weld line. Since the diaphragm is fed from a concentric sprue, uniform flow to all parts of the gate is easy to maintain. This will result in radial flow pattern developing from the gate. Though this radial flow pattern will result in residual conflicting strains, the symmetry of these strains, the resulting stresses, and the structural rigidity provided by the gear shape will generally result in the most acceptable moulding conditions. For the gear with multiple pin gating (Figure 6), the plastic is injected at several places symmetrically located. By using this type of gating, system results in a more uniform filling pattern with reasonable viscosity of plastic when the material welds, as well as creates uniform shrinkage in all direction.

From the results of filling pattern in preliminary filling analysis conducted, it is clarified that diaphragm and multiple pin gating gear strongly influence the uniformity of the transient progression of the polymer flow front in the cavity. However, the multiple-pin gating system is not economical to be used for single cavity mould due to the complexity of three plate mould machining processes which require high cost of tools production. Therefore, in this case the model gear with diaphragm gate is selected as best location gate and will be further studied in the next processing parameters optimization in CFW analysis.

2.3. Cool + Flow + Warp (CFW) Analysis. CFW analysis is conducted after the optimized gating system for the studied model gear is completely determined in the preliminary filling analysis. A systematic approach based on Taguchi method is adopted in designing the experiment. The Taguchi method is an efficient tools and widely applied in designing highquality manufacturing system [18], mechanical component [19], and process optimization [20,21]. The popularity of Taguchi method is due to its robustness in designing highquality system based on orthogonal array experiments, which provides much reduced variance for the experiment with optimum setting of process control parameters.

In this study, volumetric shrinkage and deflection were selected as response variables to characterize and evaluate the gear simulation model related to injection moulding process parameters. These two quality characteristics are carefully chosen as controlling features to be studied due to its impact on the quality of final moulded gear to be produced in future. Shrinkage and deflection negatively influence the dimensional stability and accuracy of the involute profile, concentricity, roundness, tooth spacing uniformity, and the size of the gear, hence, impacting the quality of the end moulded gear, noise, vibration, and product life. In this study, the-lower-the-better quality characteristic or, in other words, the minimum volumetric shrinkage and deflection are 


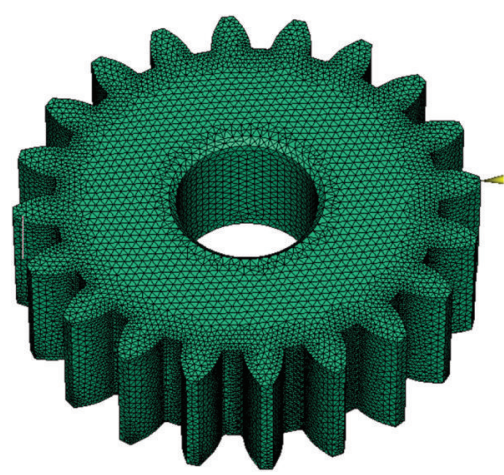

(a) side gate

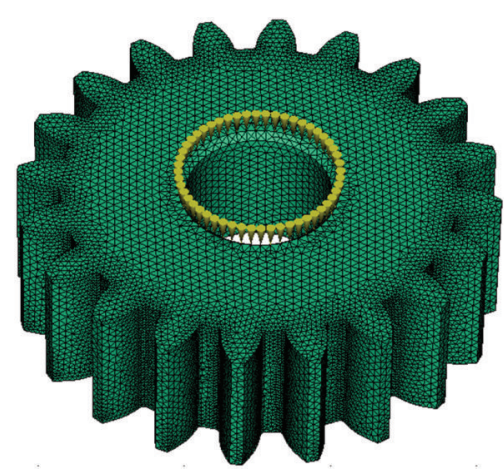

(b) diaphragm gate

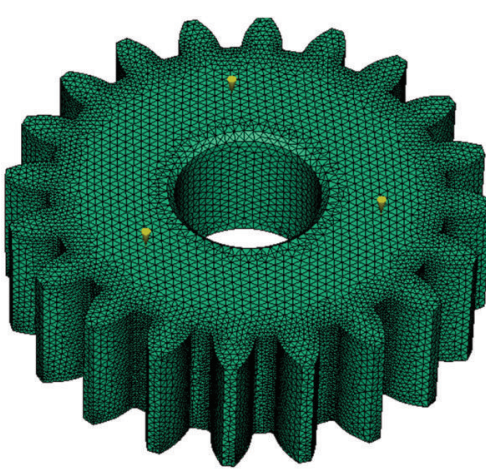

(c) multiple-pin gate

FIgURE 3: Three different types and locations of gates for the model gear.

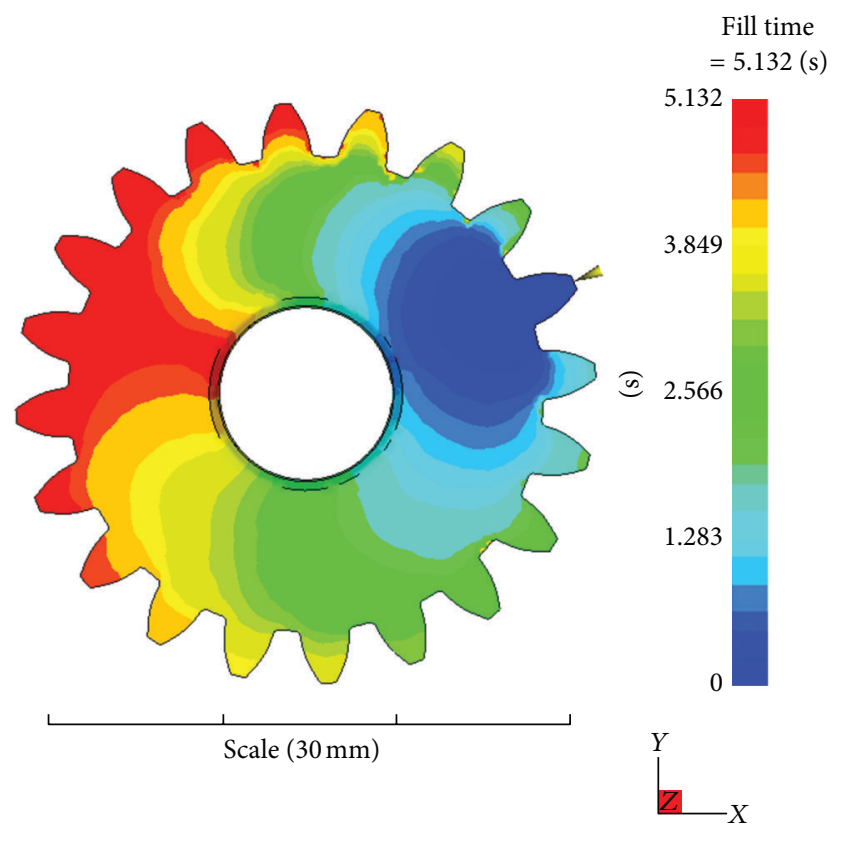

FIGURE 4: Filling pattern for side gating gear.

preferable in studying the effects of processing parameters on the moulded gear. After careful examination of all possible parameters that can affect the quality characteristics, six processing parameters (melt temperature, mould temperature, packing pressure, packing time, injection time and cooling time) were selected and were varied to obtain optimum levels of parameters for acceptable quality. The injection moulding process parameters, and their levels used in conducting the MPI simulation are shown in Table 2.

After determining the number of processing parameters and their levels, an appropriate orthogonal array (OA) has to be established for laying out the design of the experiment that needs to be conducted. The Taguchi's OA is an attempt to uncover subtle interactions among process variables with a small fraction of all possible combinations. Ilzarbe et al. [22] reported that Taguchi's OA achieved the highest usage in engineering application with $31 \%$, outweighing other types

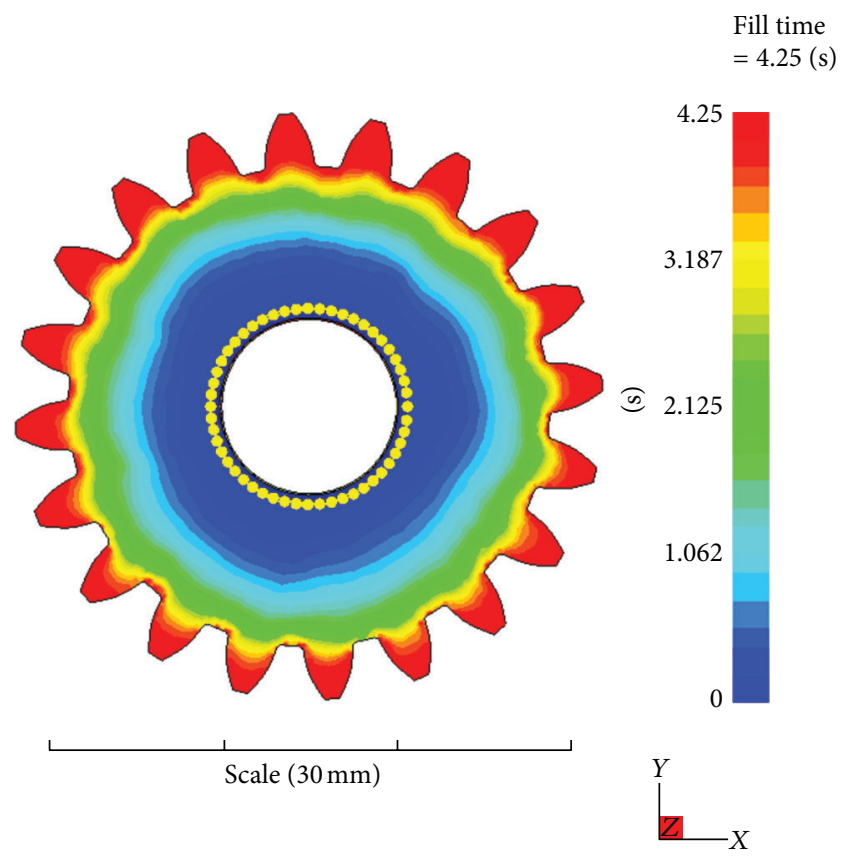

FIGURE 5: Filling pattern for diaphragm gating gear.

TABLE 2: Injection moulding parameters and their levels.

\begin{tabular}{lcccc}
\hline Column & Factors & Level 1 & Level 2 & Level 3 \\
\hline$A$ & Melt temperature $\left({ }^{\circ} \mathrm{C}\right)$ & 200 & 230 & 260 \\
$B$ & Mold temperature $\left({ }^{\circ} \mathrm{C}\right)$ & 20 & 30 & 50 \\
$C$ & Packing pressure $(\%)$ & $60 \%$ & $80 \%$ & $120 \%$ \\
$D$ & Packing time (s) & 5 & 10 & 30 \\
$E$ & Injection time (s) & 1 & 2 & 3 \\
$F$ & Cooling time (s) & 10 & 30 & 50 \\
\hline
\end{tabular}

of experimental design due to its practicality. The selection of the OA is concerned with the total degree of freedom (DOF) of the injection moulding process parameters. The DOF is defined as the number of comparisons among the process parameters required to optimize the parameters. In this study, there are six injection moulding process parameters each with 


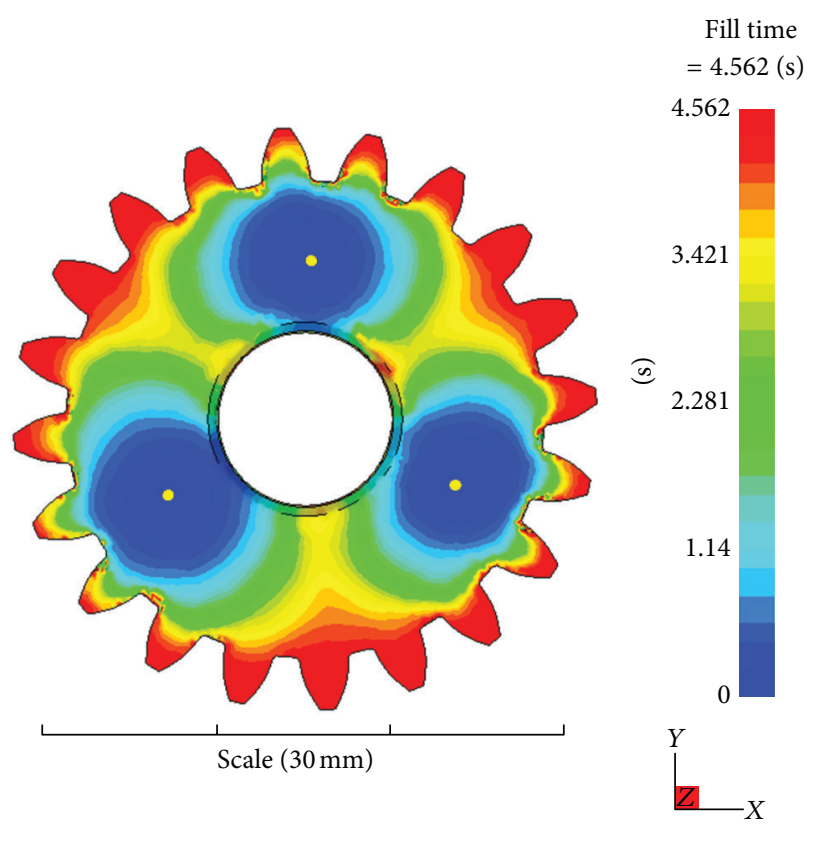

FIGURE 6: Filling pattern for multiple pin gating gear.

TABLE 3: Design of experiment using $\mathrm{L}_{18}\left(2^{1}, 3^{7}\right)$.

\begin{tabular}{lllllllll}
\hline \multirow{2}{*}{ Factors no/trials no } & 1 & 2 & 3 & 4 & 5 & 6 & 7 & 8 \\
& & $A$ & $B$ & $C$ & $D$ & $E$ & $F$ & \\
\hline 1 & 1 & 1 & 1 & 1 & 1 & 1 & 1 & 1 \\
2 & 1 & 1 & 2 & 2 & 2 & 2 & 2 & 2 \\
3 & 1 & 1 & 3 & 3 & 3 & 3 & 3 & 3 \\
4 & 1 & 2 & 1 & 1 & 2 & 2 & 3 & 3 \\
5 & 1 & 2 & 2 & 2 & 3 & 3 & 1 & 1 \\
6 & 1 & 2 & 3 & 3 & 1 & 1 & 2 & 2 \\
7 & 1 & 3 & 1 & 2 & 1 & 3 & 2 & 3 \\
8 & 1 & 3 & 2 & 3 & 2 & 1 & 3 & 1 \\
9 & 1 & 3 & 3 & 1 & 3 & 2 & 1 & 2 \\
10 & 2 & 1 & 1 & 3 & 3 & 2 & 2 & 1 \\
11 & 2 & 1 & 2 & 1 & 1 & 3 & 3 & 2 \\
12 & 2 & 1 & 3 & 2 & 2 & 1 & 1 & 3 \\
13 & 2 & 2 & 1 & 2 & 3 & 1 & 3 & 2 \\
14 & 2 & 2 & 2 & 3 & 1 & 2 & 1 & 3 \\
15 & 2 & 2 & 3 & 1 & 2 & 3 & 2 & 1 \\
16 & 2 & 3 & 1 & 3 & 2 & 3 & 1 & 2 \\
17 & 2 & 3 & 2 & 1 & 3 & 1 & 2 & 3 \\
18 & 2 & 3 & 3 & 2 & 1 & 2 & 3 & 1 \\
\hline
\end{tabular}

three levels. By neglecting the interaction among the injection moulding parameters, the total DOF is twelve. The DOF for the OA should be greater than or at least equal to that of the process parameters. Thereby, an $\mathrm{L}_{18}\left(2^{1}, 3^{7}\right) \mathrm{OA}$ is considered. The experimental layout as illustrated in Table 3 is used for conducting the simulation on gear model.

In Table 3, the trial numbers indicate the number of conducted simulations. In this study, 18 simulations are conducted and assigned as Trials $1-18$. Factors $A-F$ represent the processing parameters: $A$ for melt temperature, $B$ for mold temperature, $C$ for packing pressure, $D$ for packing time, $E$ for injection time, and $F$ for cooling time. All these factors are assigned to Columns 2-7. The two remaining columns (i.e., Columns 1 and 8) are eliminated and will not be used when running the experiment.

\section{Analysis Method}

The Grey relational analysis (GRA) associated with the Taguchi method is applied to analyze the data obtained in CFW analysis as well as to determine the optimal processing parameters for the desired multiple quality characteristics of the moulded plastic gear. The grey theory is based on the random uncertainty of small samples which developed into an evaluation technique to solve certain problems of system that are complex and have incomplete information. The method is a normalization evaluation technique which is extended to solve the complicated multiperformance characteristics optimization effectively.

3.1. Data Preprocessing. A data preprocessing is required in view of the fact that the range and unit in one data may differ from the others. Moreover, it is necessary when the sequence scatter range is too large or the target sequence directions are different. The data pre-processing involves the transfer of the original sequence to a comparable sequence. Let the original reference sequence and comparability sequences be represented as $x_{0}^{(\mathrm{O})}(k)$ and $x_{i}^{(\mathrm{O})}(k), i=1,2, \ldots, m ; k=$ $1,2, \ldots, n$, respectively. There are four methodologies of data pre-processing available for the GRA based on the characteristics of the data sequence as follows.

The-larger-the better characteristic is as follows:

$$
x_{i}^{*}(k)=\frac{x_{i}^{(O)}(k)-\min x_{i}^{(O)}(k)}{\max x_{i}^{(O)}(k)-\min x_{i}^{(O)}(k)} .
$$

The-smaller-the-better characteristic is as follows:

$$
x_{i}^{*}(k)=\frac{\max x_{i}^{(O)}(k)-x_{i}^{(O)}(k)}{\max x_{i}^{(O)}(k)-\min x_{i}^{(O)}(k)} .
$$

The-nominal-the-better characteristic is as follows:

$$
x_{i}^{*}(k)=1-\frac{\left|x_{i}^{(O)}(k)-O B\right|}{\max \left\{\max x_{i}^{(O)}(k)-O B, O B-\min x_{i}^{(O)}(k)\right\}} \text {. }
$$

Alternatively, the original sequence can be normalized using the simplest methodology in which the values of the original sequence can be divided by the first value of the sequence:

$$
x_{i}^{*}(k)=\frac{x_{i}^{(O)}(k)}{x_{i}^{(O)}(1)},
$$

where $x_{i}^{(\mathrm{O})}(k)=$ the original sequence, $x_{i}^{*}(k)=$ the sequence after the data preprocessing, $\max x_{i}^{(O)}(k)=$ the largest value of $x_{i}^{(\mathrm{O})}(k)$, and $\min x_{i}^{(\mathrm{O})}(k)=$ the smallest value of $x_{i}^{(\mathrm{O})}(k)$. 
TABLE 4: Experimental results of multiple quality characteristic for gear model.

\begin{tabular}{|c|c|c|c|c|c|c|c|c|}
\hline \multirow{2}{*}{ Experimental run } & \multicolumn{6}{|c|}{ Factors } & \multirow{2}{*}{ Volumetric shrinkage (\%) } & \multirow{2}{*}{ Deflection (mm) } \\
\hline & $A$ & $B$ & $C$ & $D$ & $E$ & $F$ & & \\
\hline 1 & 200 & 20 & 60 & 5 & 1 & 10 & 18.37 & 0.4375 \\
\hline 2 & 200 & 30 & 80 & 10 & 2 & 30 & 19.06 & 0.3740 \\
\hline 3 & 200 & 50 & 120 & 30 & 3 & 50 & 19.47 & 0.3576 \\
\hline 4 & 230 & 20 & 60 & 10 & 2 & 50 & 20.25 & 0.3966 \\
\hline 5 & 230 & 30 & 80 & 30 & 3 & 10 & 20.13 & 0.3510 \\
\hline 6 & 230 & 50 & 120 & 5 & 1 & 30 & 21.02 & 0.5374 \\
\hline 7 & 260 & 20 & 80 & 5 & 3 & 30 & 22.26 & 0.5851 \\
\hline 8 & 260 & 30 & 120 & 10 & 1 & 50 & 23.27 & 0.4294 \\
\hline 9 & 260 & 50 & 60 & 30 & 2 & 10 & 22.41 & 0.3835 \\
\hline 10 & 200 & 20 & 120 & 30 & 2 & 30 & 18.70 & 0.3444 \\
\hline 11 & 200 & 30 & 60 & 5 & 3 & 50 & 19.27 & 0.4254 \\
\hline 12 & 200 & 50 & 80 & 10 & 1 & 10 & 18.31 & 0.3921 \\
\hline 13 & 230 & 20 & 80 & 30 & 1 & 50 & 21.03 & 0.3606 \\
\hline 14 & 230 & 30 & 120 & 5 & 2 & 10 & 20.28 & 0.5127 \\
\hline 15 & 230 & 50 & 60 & 10 & 3 & 30 & 20.04 & 0.3857 \\
\hline 16 & 260 & 20 & 120 & 10 & 3 & 10 & 22.33 & 0.4080 \\
\hline 17 & 260 & 30 & 60 & 30 & 1 & 30 & 23.27 & 0.3828 \\
\hline 18 & 260 & 50 & 80 & 5 & 2 & 50 & 22.46 & 0.6049 \\
\hline
\end{tabular}

3.2. Grey Relational Coefficient and Grey Relational Grade. Following data preprocessing, a grey relational coefficient can be calculated with the preprocessed sequences. The grey relational coefficient is defined as follows:

$$
\begin{gathered}
\gamma\left[x_{0}^{*}(k), x_{i}^{*}(k)\right]=\frac{\Delta_{\min }+\zeta \Delta_{\max }}{\Delta_{0 i}(k)+\zeta \Delta_{\max }}, \\
0<\gamma\left[x_{0}^{*}(k), x_{i}^{*}(k)\right] \leq 1
\end{gathered}
$$

where $\Delta_{0 i}(k)$ is the deviation sequence of the reference sequence, $x_{0}^{*}(k)$ is the comparability sequence, $x_{i}^{*}(k)$; namely,

$$
\begin{aligned}
& \Delta_{0 i}(k)=\left|x_{0}^{*}(k)-x_{i}^{*}(k)\right|, \\
& \Delta_{\max }=\min _{\forall j \in i} \max _{\forall k}\left|x_{0}^{*}(k)-x_{j}^{*}(k)\right|, \\
& \Delta_{\min }=\min _{\forall j \in i} \min _{\forall k}\left|x_{0}^{*}(k)-x_{j}^{*}(k)\right| \\
& \zeta=\text { distinguishing coefficient } \zeta \in|0,1| .
\end{aligned}
$$

On the other hand, the grey relational grade is a weighting sum of the grey relational coefficient and is defined as follows:

$$
\begin{aligned}
\gamma\left(x_{0}^{*}, x_{i}^{*}\right)= & \sum_{k=1}^{n} \beta_{k} \gamma\left[x_{0}^{*}(k), x_{i}^{*}(k)\right], \\
& \sum_{k=1}^{n} \beta_{k}=1 .
\end{aligned}
$$

Here, the grey relational grade $\gamma\left(x_{0}^{*}, x_{i}^{*}\right)$ represents the level of correlation between the reference sequence and the comparability sequence. If the two sequences are identically coincidence, then the value of grey relational grade is equal to one. The grey relational grade also indicates the degree of influence that the comparability sequence could exert on the reference sequence. Therefore, if a particular comparability sequence is more important to the reference sequence than the other comparability sequences, the grey relational grade for that comparability sequence and reference sequence will exceed that for other grey relational grades. Grey relational analysis is actually a measurement of absolute value of data difference between sequences and could be used to measure approximation correlation between sequences.

\section{Analysis and Discussion of Experimental Results}

4.1. The Optimum Injection Moulding Process Parameters. The results of volumetric shrinkage and deflection of the gear model with the optimized diaphragm gating system for different combination of injection moulding parameters of eighteen experimental runs (Table 3) are listed in Table 4. In order to find the optimum levels of melt temperature (factor $A$ ), mould temperature (factor $B$ ), packing pressure (factor $C$ ), packing time (factor $D$ ), injection time (factor $E$ ), and cooling time (factor $F$ ) for the desired multiple quality characteristics of the PP moulded gear, the results in Table 4 are needed to be normalized as the range and unit in one data are different from the others. By adopting the GRA, typically, lower values of volumetric shrinkage and deflection in the moulded gear as the target values are desirable. Thus, the data sequence have the-smaller-the-better characteristic. The values of volumetric shrinkage and deflection are set to be the reference sequence $x_{0}^{(O)}(k), k=1,2$. Moreover, the results of eighteen experiments were the comparability sequences $x_{i}^{(O)}(k), i=1,2,3, \ldots, 18, k=1,2$. Table 5 lists all of the 
TABLE 5: The sequences of each quality characteristics after data preprocessing

\begin{tabular}{lcc}
\hline & Volumetric Shrinkage (\%) & $\begin{array}{c}\text { Deflection } \\
(\mathrm{mm})\end{array}$ \\
\hline $\begin{array}{l}\text { Reference sequence } \\
\text { Comparability sequences }\end{array}$ & 1.0000 & 1.0000 \\
Experiment no. 1 & 0.9879 & \\
Experiment no. 2 & 0.8488 & 0.6426 \\
Experiment no. 3 & 0.7661 & 0.8864 \\
Experiment no. 4 & 0.6089 & 0.9493 \\
Experiment no. 5 & 0.6331 & 0.7996 \\
Experiment no. 6 & 0.4536 & 0.9747 \\
Experiment no. 7 & 0.2036 & 0.2591 \\
Experiment no. 8 & 0.0000 & 0.0760 \\
Experiment no. 9 & 0.1734 & 0.6737 \\
Experiment no. 10 & 0.9214 & 0.8499 \\
Experiment no. 11 & 0.8065 & 1.0000 \\
Experiment no. 12 & 1.0000 & 0.6891 \\
Experiment no. 13 & 0.4516 & 0.8169 \\
Experiment no. 14 & 0.6028 & 0.9378 \\
Experiment no. 15 & 0.6512 & 0.3539 \\
Experiment no. 16 & 0.1895 & 0.8415 \\
Experiment no. 17 & 0.0000 & 0.7559 \\
Experiment no. 18 & 0.1633 & 0.8526 \\
\hline
\end{tabular}

sequences following data preprocessing using (2), where the reference and comparability sequences are denoted as $x_{0}^{*}(k)$ and $x_{i}^{*}(k)$, respectively. follows:

As for the deviation sequences, $\Delta_{01}$ can be calculated as

$$
\begin{aligned}
& \Delta_{01}(1)=\left|x_{0}^{*}(1)-x_{1}^{*}(1)\right|=|1-0.9879|=0.0121, \\
& \Delta_{01}(2)=\left|x_{0}^{*}(2)-x_{1}^{*}(2)\right|=|1-0.6426|=0.3574 .
\end{aligned}
$$

So, $\Delta_{01}=(0.0121,0.3574)$.

The same calculating method was performed for $i=1-18$ and the results of all $\Delta_{0 i}$ for $i=1-18$ are listed in Table 6 .

Investigating the data presented in Table 6 , we can find that $\Delta_{\max }(k)$ and $\Delta_{\min }(k)$ are as follows:

$$
\begin{gathered}
\Delta_{\text {max }}=\Delta_{8}(1)=\Delta_{18}(2)=1.0000 \\
\Delta_{\text {min }}=\Delta_{12}(1)=\Delta_{10}(2)=0.0000 .
\end{gathered}
$$

The distinguishing coefficient $\zeta$ can be substituted for the grey relational coefficient in (5). Given that all the process parameters have equal weighting, the value of $\zeta$ is defined as 0.5 . Table 7 lists the grey relational coefficient and grade for all eighteen comparability sequences.

In order to calculate the average grey relational grade for each injection moulding parameters level, the main effects' analysis of the Taguchi method was employed. It was done by sorting the grey relational grades corresponding to levels of the injection moulding parameters in each column of the orthogonal array, and taking an average on those with
TABLE 6: The deviation sequences.

\begin{tabular}{lll}
\hline Deviation sequences & $\Delta_{0 i}(1)$ & $\Delta_{0 i}(2)$ \\
\hline Experiment no. 1 & 0.0121 & 0.3574 \\
Experiment no. 2 & 0.1512 & 0.1136 \\
Experiment no. 3 & 0.2339 & 0.0507 \\
Experiment no. 4 & 0.3911 & 0.2004 \\
Experiment no. 5 & 0.3669 & 0.0253 \\
Experiment no. 6 & 0.5464 & 0.7409 \\
Experiment no. 7 & 0.7964 & 0.9240 \\
Experiment no. 8 & 1.0000 & 0.3263 \\
Experiment no. 9 & 0.8266 & 0.1501 \\
Experiment no. 10 & 0.0786 & 0.0000 \\
Experiment no. 11 & 0.1935 & 0.3109 \\
Experiment no. 12 & 0.0000 & 0.1831 \\
Experiment no. 13 & 0.5484 & 0.0622 \\
Experiment no. 14 & 0.3972 & 0.6461 \\
Experiment no. 15 & 0.3488 & 0.1585 \\
Experiment no. 16 & 0.8105 & 0.2441 \\
Experiment no. 17 & 1.0000 & 0.1474 \\
Experiment no. 18 & 0.8367 & 1.0000 \\
\hline
\end{tabular}

the same level. For instance, for the factor $A$ (as shown in Table 3), experiments Nos. 1, 2, 3, 10, 11, and 12 were set at level 1. Therefore, the average grey relational grade for $A_{1}$ can calculated as follows:

$$
\begin{aligned}
\bar{A}_{1} & \\
= & \frac{(0.7798+0.7913+0.7947+0.9321+0.6687+0.8660)}{6} \\
= & 0.8054 .
\end{aligned}
$$

Similarly, the average grey relational grades for $A_{2}$ and $A_{3}$ are calculated as follows:

$$
\begin{aligned}
\bar{A}_{2} & \\
& =\frac{(0.6375+0.7643+0.4404+0.6832+0.4968+0.6742)}{6} \\
& =0.6160, \\
\bar{A}_{3} & \\
& =\frac{(0.3684+0.4692+0.5730+0.5267+0.5528+0.3537)}{6} \\
& =0.4740 .
\end{aligned}
$$

Using the similar method, calculations were performed for each injection moulding parameter level and the main effects' analysis was constructed as shown in Table 8 and plotted in Figure 7.

In view of the fact that the grey relational grade represents the level of correlation between the reference and 
TABLE 7: The grey relational coefficient and grey relational grade for eighteen comparability sequences.

\begin{tabular}{lccc}
\hline Experimental run (comparability sequences) & Volumetric shrinkage (\%) & Deflection (mm) & Grey relational grade \\
\hline 1 & Grey relational coefficient & 0.5832 & 0.7798 \\
2 & 0.9764 & 0.8148 & 0.7913 \\
3 & 0.7678 & 0.9080 & 0.7947 \\
4 & 0.6813 & 0.7139 & 0.6375 \\
5 & 0.5611 & 0.9518 & 0.7643 \\
6 & 0.5767 & 0.4029 & 0.4404 \\
7 & 0.4778 & 0.3511 & 0.3684 \\
8 & 0.3857 & 0.6051 & 0.4692 \\
9 & 0.3333 & 0.7691 & 0.5730 \\
10 & 0.3769 & 1.0000 & 0.9321 \\
11 & 0.8641 & 0.6166 & 0.6687 \\
12 & 0.7209 & 0.7319 & 0.8660 \\
13 & 1.0000 & 0.8894 & 0.6832 \\
14 & 0.4769 & 0.4363 & 0.4968 \\
15 & 0.5573 & 0.7593 & 0.6742 \\
16 & 0.5891 & 0.6719 & 0.5267 \\
18 & 0.3815 & 0.7723 & 0.3533 \\
\hline
\end{tabular}

TABLE 8: The main effect analysis for grey relational grade.

\begin{tabular}{lcccc}
\hline Column & Parameters & Level 1 & Level 2 & Level 3 \\
\hline$A$ & Melt temperature $\left({ }^{\circ} \mathrm{C}\right)$ & 0.8054 & 0.6160 & 0.4740 \\
$B$ & Mould temperature $\left({ }^{\circ} \mathrm{C}\right)$ & 0.6546 & 0.6239 & 0.6170 \\
$C$ & Packing pressure $(\%)$ & 0.6477 & 0.6378 & 0.6100 \\
$D$ & Packing time (s) & 0.5180 & 0.6608 & 0.7167 \\
$E$ & Injection time (s) & 0.6319 & 0.6307 & 0.6328 \\
$F$ & Cooling time (s) & 0.6678 & 0.6265 & 0.6012 \\
\hline
\end{tabular}

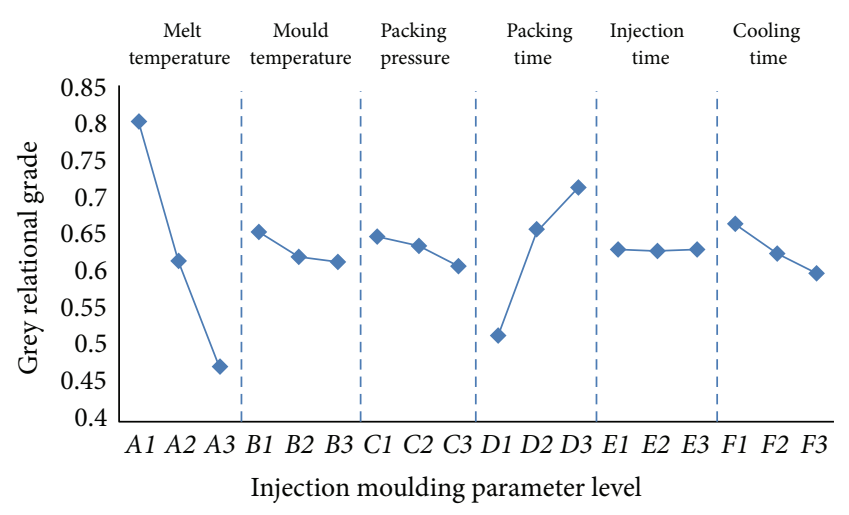

FIGURE 7: Main effects plot for grey relational grade.

the comparability sequences, the larger grey relational grade means that the comparability sequence exhibits a stronger correlation with the reference sequence. Basically, the larger the grey relational grade, the better the multiple quality characteristics are. From Figure 7, it is clearly shown that the multiple quality characteristics of the PP moulded gear with optimized diaphragm gating system are greatly influenced by the adjustments of the processing parameters. Considering multiple quality characteristic in terms of volumetric shrinkage and deflection, two opposite trends are observed where the increment of melt temperature, mould temperature, packing pressure, and cooling time result in greater volumetric shrinkage and deflection of the moulded gear. On the contrary, the increment of packing time and injection time reduces the volumetric shrinkage and deflection.

As in this case, the best combination of processing parameters and levels could easily be obtained from the main effect analysis by selecting the level of each parameter with the highest grey relational grade. Referring to Figure 4, $A_{1}, B_{1}, C_{1}, D_{3}, E_{3}$, and $F_{1}$ show the largest value of grey relational grade for factors $A, B, C, D, E$, and $F$, respectively. As a result, the optimal parameter setting which statistically results in the minimum volumetric shrinkage, as well as deflection for the PP moulded gear, is predicted to be $A_{1} B_{1} C_{1} D_{3} E_{3} F_{1}$. Restated, the melt temperature is $200^{\circ} \mathrm{C}$, mould temperature is $20^{\circ} \mathrm{C}$, packing pressure is $60 \%$, packing time is $30 \mathrm{~s}$, injection time is $3 \mathrm{~s}$, and cooling time is $10 \mathrm{~s}$.

From the result of optimum combination of processing parameters and levels, the increasing of melt temperature of PP seems to not greatly improve the ability of the molten material to flow through a thin section of the diaphragm gate to the cavity of the mould. However, since the diaphragm is fed from a concentric sprue, uniform flow to all parts of the gate is easy to maintain, which has enhanced the filling rate or the injection time of the molten material to be filled in the cavity. Therefore, greater time for the molten material to be filled in the cavity is expected to result in minimum volumetric shrinkage and deflection of the moulded gear. The way of the diaphragm gate has been attached to the gear cavity 
TABLE 9: ANOVA table for the grey relational grade for eighteen comparability sequences.

\begin{tabular}{|c|c|c|c|c|c|c|}
\hline Column & Parameters & DOF & $S$ & $V$ & $F$ & $\%$ \\
\hline$A$ & Melt temperature $\left({ }^{\circ} \mathrm{C}\right)$ & 2 & 0.3318 & 0.1659 & 81.264 & 67.579 \\
\hline$B$ & Mold temperature $\left({ }^{\circ} \mathrm{C}\right)$ & 2 & 0.0048 & 0.0024 & 1.180 & 0.981 \\
\hline C & Packing pressure (\%) & 2 & 0.0046 & 0.0023 & 1.123 & 0.934 \\
\hline$D$ & Packing time (s) & 2 & 0.1260 & 0.0630 & 30.861 & 25.664 \\
\hline$E$ & Injection time (s) & 2 & 0.0000 & 0.0000 & 0.003 & 0.003 \\
\hline$F$ & Cooling time (s) & 2 & 0.0136 & 0.0068 & 3.320 & 2.761 \\
\hline All others/error & & 5 & 0.0102 & 0.0020 & & 2.079 \\
\hline Total & & 17 & 0.4910 & & & 100.000 \\
\hline
\end{tabular}

is greatly influencing the determination of optimum packing and cooling process in the mould. The packing pressure of $60 \%$ and packing time of $30 \mathrm{~s}$ as well as cooling time of $10 \mathrm{~s}$ are recognized to be the optimum packing and cooling for the minimum volumetric shrinkage and deflection in the studied moulded gear.

4.2. The Significance of Injection Moulding Parameters. In order to examine the extent to which injection moulding parameters significantly influence the performance of moulded gear, analysis of variance (ANOVA) of the Taguchi method is performed on the grey relational grade for eighteen comparability sequences (Table 7). The computed quantity of degrees of freedom $(\mathrm{DOF})$, sum of square $(S)$, variance $(V)$, $F$-ratio $(F)$, and percentage contribution (\%) are presented in Table 9.

In ANOVA, the $F$-ratio which is also known as variance ratio, denoted as $F$ in the Table 9 , is used to identify the significance of the processing parameters by performing a test of significance against the error term at a desired confidence level. A large value of $F$ will result in high percentage contribution, indicating the relative importance ranking of the processing parameters in influencing the quality characteristics. However, the processing parameters with highest percentage contribution need not necessarily be significant because only the computed $F$-ratios of the processing parameters which are greater than the $F$-Table of specific confidence level are statistically considered as significant [23]

In the present study, the degrees of freedom for the numerator is 2 and that for the denominator is 5, from the $F$-Table at 0.01 level of significance ( $99 \%$ confidence), the obtained result $F 0.01(2,5)=13.274$. Referring to Table 9, out of six processing parameters, only two parameters, including melt temperature and packing time, are considered as significant as their $F$-ratios and are greater than the threshold values obtained from the F-Table of $99 \%$ confidence level.

As shown in Table 9, it can be observed that the melt temperature is the most influential processing parameter which demonstrates the strongest comparability sequence among the injection moulding processing parameters, with the percentage contribution of $67.579 \%$. The analysis revealed that the melt temperature had the strongest correlation with the volumetric shrinkage and deflection in the moulded gear for the specific material selected. Nevertheless, injection time was found to have the least importance on volumetric shrinkage and deflection concurrently with the lower percentage contribution of only $0.003 \%$.

\section{Conclusions}

The findings of simulation experiment reveal that the advancement of the simulation packages is capable of simulating the scenarios of the polymer melt without conducting the real experiment. As in this study, MPI software is a useful tool to predict volumetric shrinkage and deflection of the moulded gear under different process conditions. The integration of the grey-based Taguchi optimization method and numerical simulation provides designers and engineers with a systematic and efficient approach to identify the most significant processing parameters on the quality characteristics of the final moulded gear out of numerous processing variables with minimal simulation trials required. Through a series of analysis and optimization, it was found out that gate types and locations have a great influence on the filling pattern or the transient progression of the polymer flow front within the feed system and mould cavity. Predicting and visualizing the filling pattern in mould cavity using simulation packages before the real manufacturing process takes place reduces the incurring high production cost due to subsequent mould modification in production line as well as minimizing the potential aesthetic issues in the moulded gear. From the main effect analysis of the average grey relational grade, it was also found that the largest value of grey relational grade for melt temperature, mould temperature, packing pressure, packing time, injection time, and cooling time were $220^{\circ} \mathrm{C}$, $20^{\circ} \mathrm{C}, 60 \%, 30 \mathrm{~s}, 3 \mathrm{~s}$, and $10 \mathrm{~s}$, respectively. Therefore, the optimal combination of processing parameters for producing a moulded gear with the minimum volumetric shrinkage and deflection was determined as $A_{1}, B_{1}, C_{1}, D_{3}, E_{3}$, and $F_{1}$ when multiple quality characteristics are simultaneously considered. Out of six important injection moulding process parameters investigated in this study, only two parameters, including melt temperature and packing time, are considered as significant on the examined quality characteristics of the moulded gear. The melt temperature showed the strongest comparability sequence with the percentage contribution of $67.579 \%$ followed by packing time of $25.664 \%$. Injection time was found to have least importance on volumetric shrinkage 
and deflection concurrently with the lower percentage contribution of only $0.003 \%$.

\section{Acknowledgment}

The authors acknowledge the Research Grant provided by University Sains Malaysia, Pulau Pinang, for funding the study that resulted in this paper.

\section{References}

[1] H. Imrek, "Performance improvement method for Nylon 6 spur gears," Tribology International, vol. 42, no. 3, pp. 503-510, 2009.

[2] K. Mao, W. Li, C. J. Hooke, and D. Walton, "Friction and wear behaviour of acetal and nylon gears," Wear, vol. 267, no. 1-4, pp. 639-645, 2009.

[3] K. Mao, "A new approach for polymer composite gear design," Wear, vol. 262, no. 3-4, pp. 432-441, 2007.

[4] S. Senthilvelan and R. Gnanamoorthy, "Effect of gear tooth fillet radius on the performance of injection molded Nylon 6/6 gears," Materials and Design, vol. 27, no. 8, pp. 632-639, 2006.

[5] S. Senthilvelan and R. Gnanamoorthy, "Damage mechanisms in injection molded unreinforced, glass and carbon reinforced nylon 66 spur gears," Applied Composite Materials, vol. 11, no. 6, pp. 377-397, 2004.

[6] A. R. Breeds, S. N. Kukureka, K. Mao, D. Walton, and C. J. Hooke, "Wear behaviour of acetal gear pairs," Wear, vol. 166, no. 1, pp. 85-91, 1993.

[7] C. J. Hooke, K. Mao, D. Walton, A. R. Breeds, and S. N. Kukureka, "Measurement and prediction of the surface temperature in polymer gears and its relationship to gear wear," Journal of Tribology, vol. 115, no. 1, pp. 119-124, 1993.

[8] E. Letzelter, J.-P. de Vaujany, L. Chazeau, and M. Guingand, "Quasi-static load sharing model in the case of Nylon 6/6 cylindrical gears," Materials and Design, vol. 30, no. 10, pp. 4360-4368, 2009.

[9] T. Osman and Ph. Velex, "A model for the simulation of the interactions between dynamic tooth loads and contact fatigue in spur gears," Tribology International, vol. 46, pp. 84-96, 2012.

[10] K. Terashima, N. Tukamoto, and N. Nishida, "Development of plastic gears for power transmission: design on load-carrying capacity ," Bulletin of the Japan Society of Mechanical Engineers , vol. 29, no. 250, pp. 1326-1329, 1986.

[11] C. Kim, H. Ahn, and T. Chong, "Reciprocating sliding wear of nylon and polyacetal against steel," Transactions of the Korean Society of Mechanical Engineers A, vol. 24, no. 3, pp. 786-793, 2000.

[12] M. Kurokawa, Y. Uchiyama, T. Iwai, and S. Nagai, "Performance of plastic gear made of carbon fiber reinforced polyamide 12," Wear, vol. 254, no. 5-6, pp. 468-473, 2003.

[13] I. Matin, M. Hadzistevic, J. Hodolic, D. Vukelic, and D. Lukic, "A CAD/CAE-integrated injection mold design system for plastic products," International Journal of Advanced Manufacturing Technology, vol. 63, no. 5-8, pp. 595-607, 2012.

[14] A. Luscher, D. Houser, and C. Snow, "An investigation of the geometry and transmission error of injection molded gears," Journal of Injection Molding Technology, vol. 4, no. 4, pp. 177190, 2000.
[15] M. J. Reig, V. J. Segui, and J. D. Zamanillo, "Rheological behavior modeling of recycled ABS/PC blends applied to injection molding process," Journal of Polymer Engineering, vol. 25, no. 5, pp. 435-457, 2005.

[16] H. Sadabadi and M. Ghasemi, "Effects of some injection molding process parameters on fiber orientation tensor of short glass fiber polystyrene composites (SGF/PS)," Journal of Reinforced Plastics and Composites, vol. 26, no. 17, pp. 1729-1741, 2007.

[17] MoldFlow Corporation, MoldFlow Plastic Insight Release 6.1, MoldFlow, Framingham, Mass, USA, 2008.

[18] A. Mahfouz, S. A. Hassan, and A. Arisha, "Practical simulation application: evaluation of process control parameters in Twisted-Pair Cables manufacturing system," Simulation Modelling Practice and Theory, vol. 18, no. 5, pp. 471-482, 2010.

[19] H.-J. Shim and J.-K. Kim, "Cause of failure and optimization of a V-belt pulley considering fatigue life uncertainty in automotive applications," Engineering Failure Analysis, vol. 16, no. 6, pp. 1955-1963, 2009.

[20] N. S. Mohan, A. Ramachandra, and S. M. Kulkarni, "Influence of process parameters on cutting force and torque during drilling of glass-fiber polyester reinforced composites," Composite Structures, vol. 71, no. 3-4, pp. 407-413, 2005.

[21] N. M. Mehat and S. Kamaruddin, "Optimization of mechanical properties of recycled plastic products via optimal processing parameters using the Taguchi method," Journal of Materials Processing Technology, vol. 211, no. 12, pp. 1989-1994, 2011.

[22] L. Ilzarbe, M. J. Álvarez, E. Viles, and M. Tanco, "Practical applications of design of experiments in the field of engineering: a bibliographical review," Quality and Reliability Engineering International, vol. 24, no. 4, pp. 417-428, 2008.

[23] P. K. Chaulia and R. Das, "Process parameter optimization for fly ash brick by Taguchi method," Materials Research, vol. 11, no. 2, pp. 159-164, 2008. 

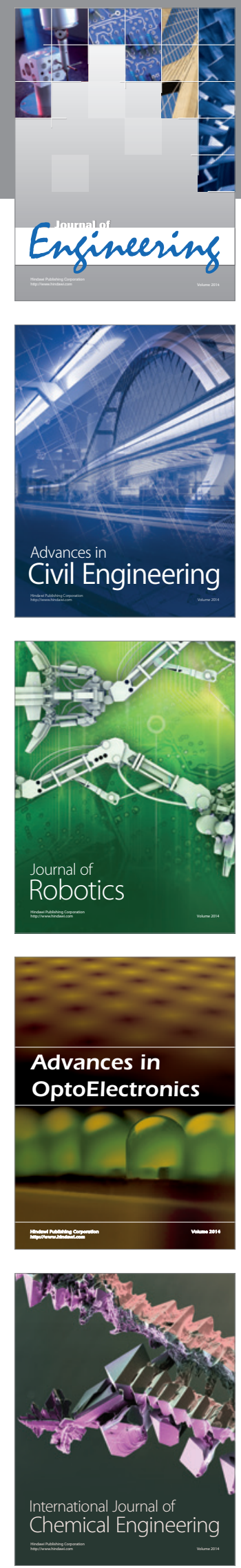

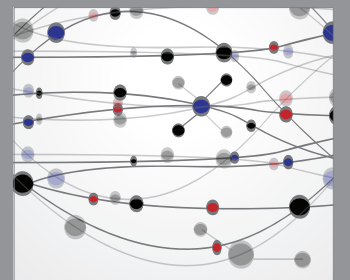

The Scientific World Journal
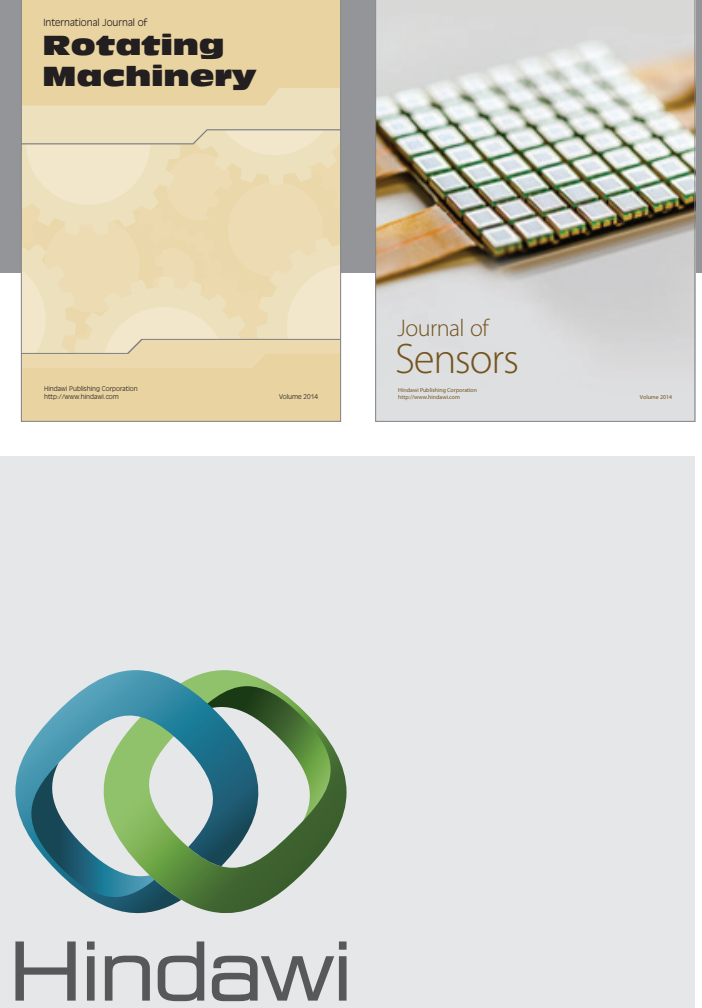

Submit your manuscripts at http://www.hindawi.com
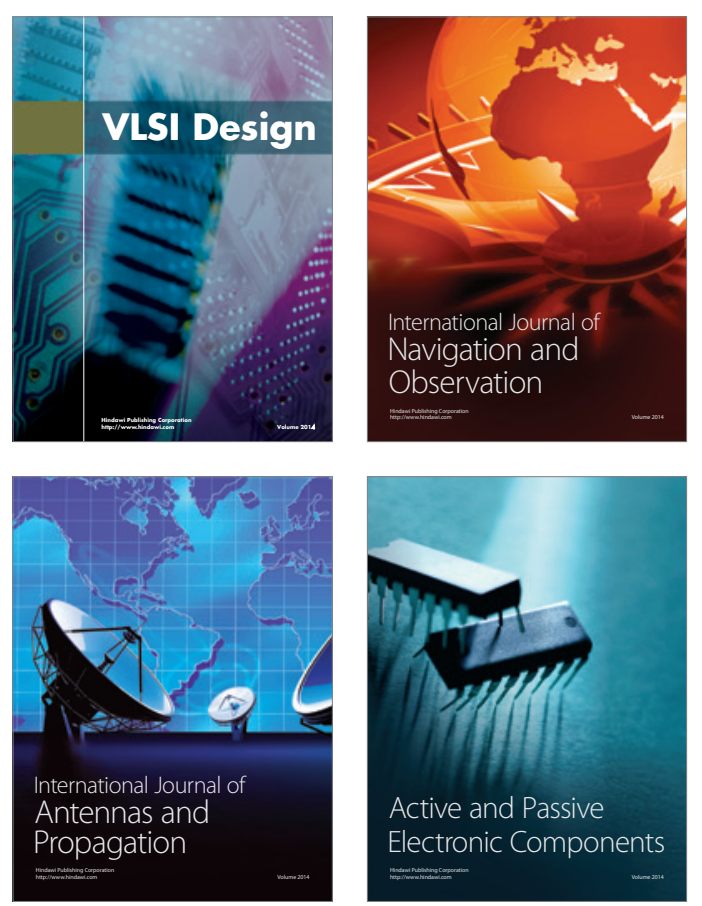
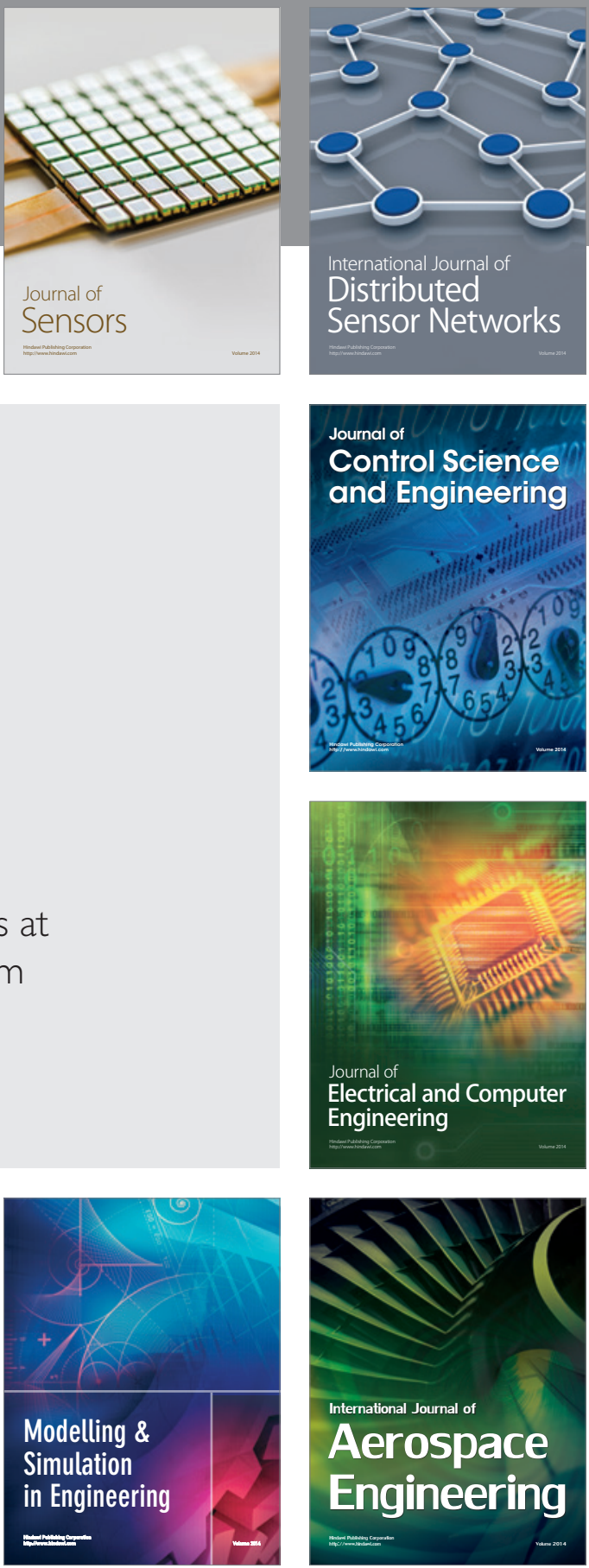

Journal of

Control Science

and Engineering
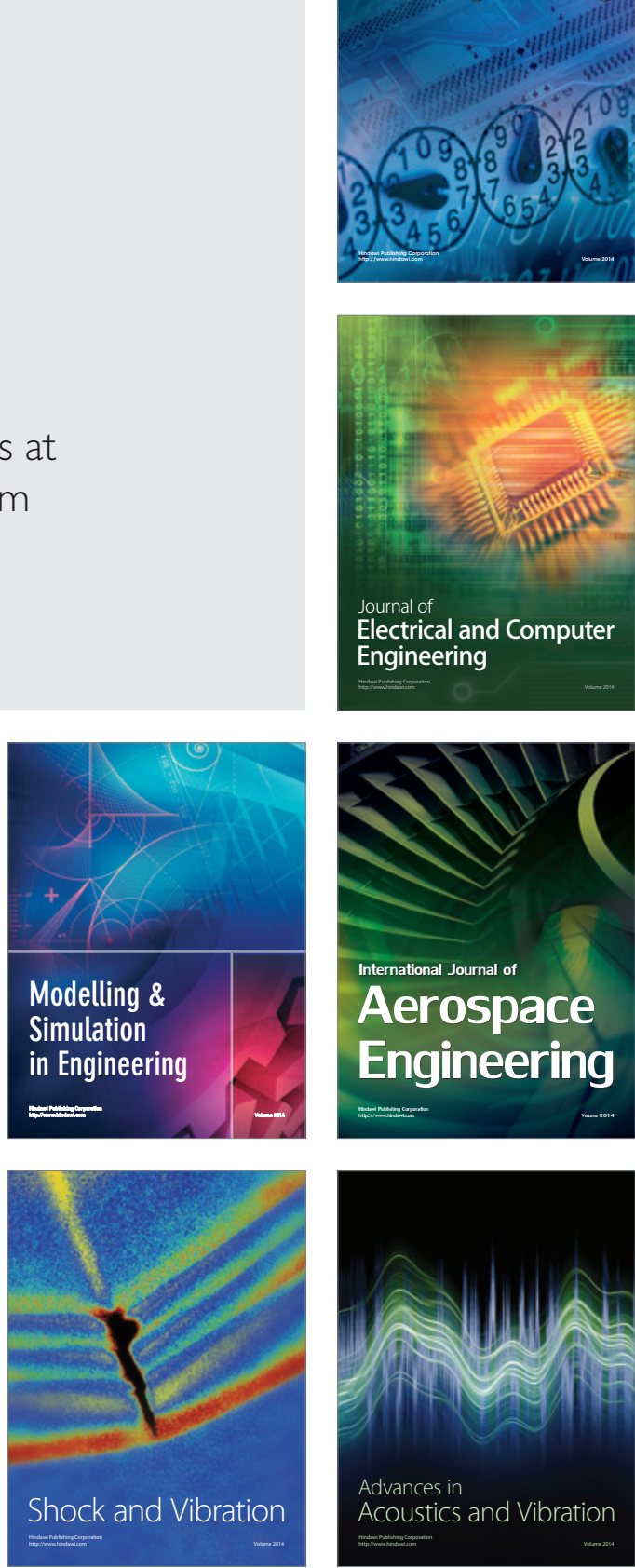